\title{
Optical Transport Network to support Digital Communications
}

\author{
${ }^{1}$ Marco Rosario Villareal, ${ }^{2}$ Oriana Rivera-Lozada, ${ }^{3}$ Luis Alberto Nuñez Lira (Corresponsal \\ author), ${ }^{4}$ Eduardo Zorrilla Tarazona, ${ }^{5}$ Zanhy Leonor Valencia-Reyes, ${ }^{6}$ Mitchell Alberto \\ Alarcón Diaz, ${ }^{7}$ Liset Sulay Rodriguez Baca
}

\author{
${ }^{1}$ Universidad Nacional de Huancavelica, Perú \\ ${ }^{2}$ Universidad Norbert Wiener, Perú \\ ${ }^{3}$ Universidad Nacional Mayor de San Marcos, Perú \\ ${ }^{4}$ Facultad de Ingeniería y Gestión Ambiental, Universidad Nacional Autónoma De Huanta, Perú \\ ${ }^{5}$ Escuela de Ingeniería Ambiental, Universidad Nacional Mayor de San Marcos \\ ${ }^{6}$ Universidad Nacional Mayor de San Marcos, Perú \\ ${ }^{7}$ Universidad Autónoma del Perú, Perú
}

Article History: Received: 11 January 2021; Accepted: 27 February 2021; Published online: 5 April 2021

\begin{abstract}
The objective of this work is to propose a solution to the problem of the lack of telecommunication services, with adequate quality of service and coverage, in the town of Choclococha, Huancavelica-Peru. For this purpose, the design and evaluation of an optical link as a backbone network and a wireless access network is presented. It is an applied and experimental research in which performance parameters were evaluated. The independent variable is the optical transport network and the dependent variable is data communication. The latter is defined by two indicators: throughput and signal reception power at the users. Both indicators were measured in a sample of the population, obtaining results that were validated with respect to the expected values according to specifications and regulations. Thus, the measured throughput exceeds the $40 \%$ data rate guaranteed by the telecommunications operator. As for the reception power, it exceeds the sensitivity level of the receiving equipment. Therefore, it is concluded that the proposed solution supports communications with optimum speed and coverage.
\end{abstract}

Keywords: communications, optical network, optical transport, optical transport

\section{Introduction}

Fiber optic networks are highly penetrated in many parts of the world. However, this is not the case in locations with low population density, subsistence economies or in rugged geographies. Currently, the Peruvian government is implementing the regional fiber optic networks projects, which are connected to the National Backbone Fiber Optic Network, a backbone already implemented that runs through all the regional capitals of Peru. The regional networks try to cover most of the cities and towns in each region, but the coverage is not $100 \%$; there are localities that are not considered and will continue to be left behind for many years [1].

There are solutions to this problem, such as satellite links, usually used for these cases, but they are usually expensive and prone to latency and low quality of service, especially due to weather conditions such as rain. Their use is usually limited, due to their high cost, to institutions and non-domestic users. Access to the Internet is necessary because it opens up a world of information and a world of opportunities only limited by the capacity and interest of each individual. Unfortunately, however, the reality in many towns in Peru is far from ideal or even close to it. A large number of localities, generally the least populated or those that are not very accessible due to their rugged geography, are in a situation of abandonment or technological isolation, seriously limiting their possibilities for development at all levels. According to official statistics and private studies [2, $3], 65 \%$ of the population of Peru's provinces do not use the Internet. Furthermore, in Peru as a whole, $81 \%$ of the population in rural areas does not use the Internet. It also indicates that the situation is more critical in the adult population (ages 25 and older) and in the lower socioeconomic levels $(\mathrm{C}$ and $\mathrm{D} / \mathrm{E})$.

The present work consists of a proposal to link the town of Choclococha with the regional optical network through a solution based on ADSS optical fiber, at 1550nm wavelength, as a transport network and wireless as an access network. This solution is similar to those used in regional networks but adapted to a specific reality in order to optimize it technologically and economically, without affecting its performance. The town of Choclococha is located in the district of Pomacocha, province of Acobamba in the Huancavelica Region. Its municipality was founded on September 10, 2014; it is located at an altitude of 3370masl and covers a land area of $106.34 \mathrm{~km} 2$. The main economic activities of the population of Choclococha are agriculture and livestock. It has a population of 1323 inhabitants as of 2015, and 486 homes. There is satellite internet access in the district, but its cost is high; the cheapest plan is $512 \mathrm{Kbps}$ at $\mathrm{S} / 950$ Soles per month. The high monthly cost of the 
service and its relatively low speed make it inaccessible to inhabitants who do not have sufficient economic resources. This is a very serious problem that discriminates against access to information sources and all the benefits and potentialities associated with this type of technological tools. Currently, optical telecommunications technologies offer a variety of products and solutions at competitive prices given the large supply and demand. Therefore, it is feasible to propose alternative solutions that do not involve waiting for the State, but rather taking advantage of regional networks through projects of specific benefit, with a shorter execution and investment time, such as the one proposed in this paper.

\section{Methodology and analysis}

The following sections describe the design of the transport and access networks carried out as part of this work. Given its size, in the case of the transport network, only the design of the external plant and the calculation of the optical power budget are considered. In the case of the access network, the design of the wireless coverage in the locality by means of sectorial antennas is considered.

\subsection{Conveyor network - outside plant}

Due to the geographic proximity, it was considered to lay fiber optics for the town of Choclococha taking as feeder node the Pomacocha Node $\left(12^{\circ} 52^{\prime} 27^{\prime \prime} \mathrm{S} 74^{\circ} 31^{\prime} 54^{\prime \prime} \mathrm{W}\right)$ located in the district of the same name in the province of Acobamba, at an altitude of 3150 meters above sea level. The design starts with the field collection of information of the poles along the electrical network and their georeferencing with GPS. This information was loaded into Basecamp software as shown in Figure 1 [4] and the route of the optical cable laying was generated in a KML file that can be viewed in Google Earth (see Results section). Then, in Excel, the hardware requirements were elaborated, as well as the metering of the optical cable between poles was defined: sag, span, type of cable according to span and sag, among others. The criteria followed for the design are shown in Table 1 to Table 5. In Table 1, the maximum allowed span of the optical cable is indicated, they are selected according to the existing separation between poles. The optical cable is fastened to the electrical poles by means of hardware accessories; among them are the suspension and retention fittings. There are different types according to the pole (new or existing) and the span of the optical cable (Table 6). According to the data collected, the transport network considers the deployment of $2.81 \mathrm{~km}$ of ADSS fiber optic cable, suitable for laying over electrical networks (in this case, medium voltage) and on the right of way of the road network with new poles parallel to the road [5]. Figure 2 shows pole 8 with the characteristics of the structure. Figure 3 shows the suspension and retention hardware for new poles.

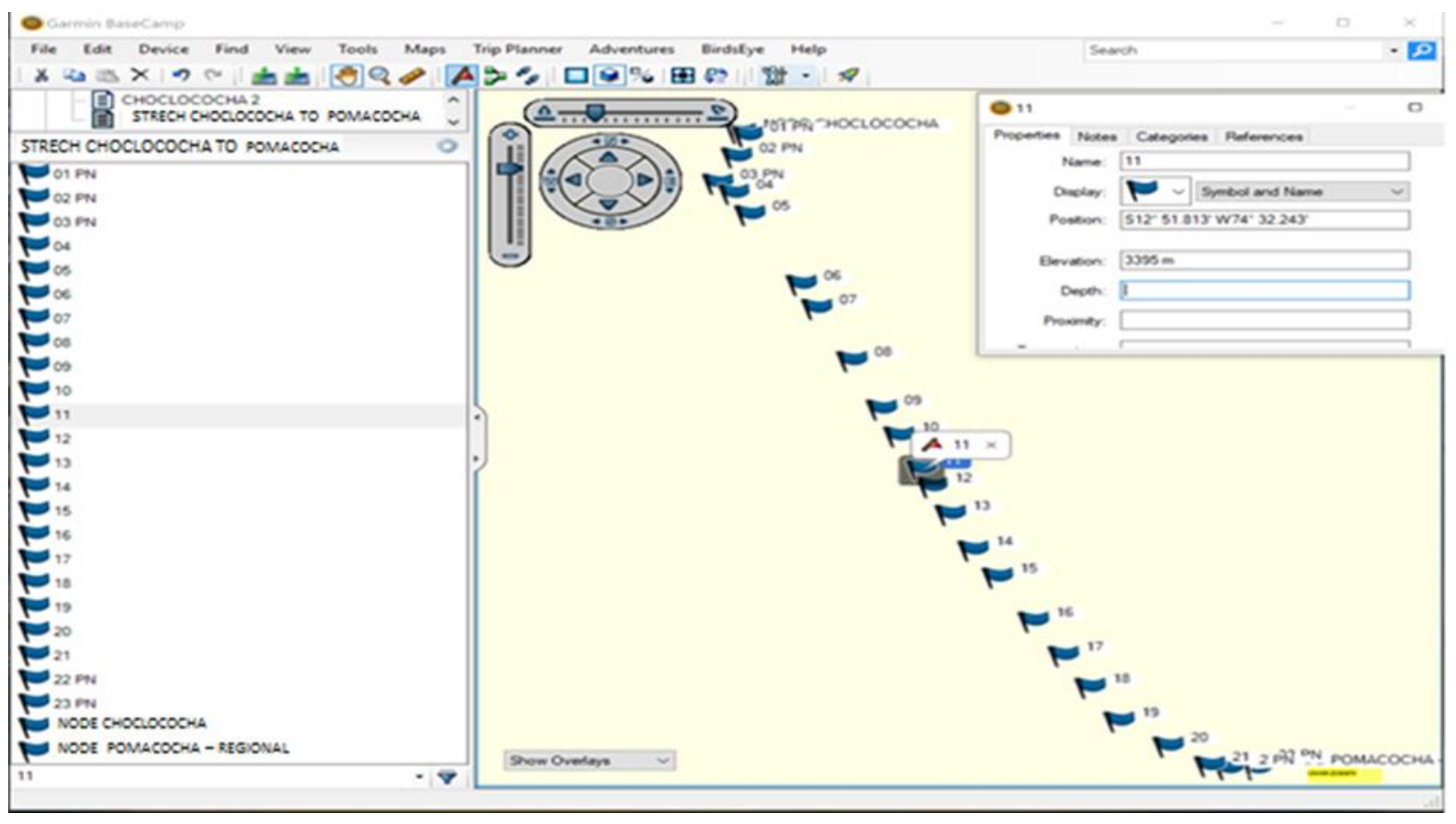

Figure 1. Database with georeferencing information (coordinates and height) of existing and new poles obtained with a Garmin GPS device. Source: Author's elaboration 


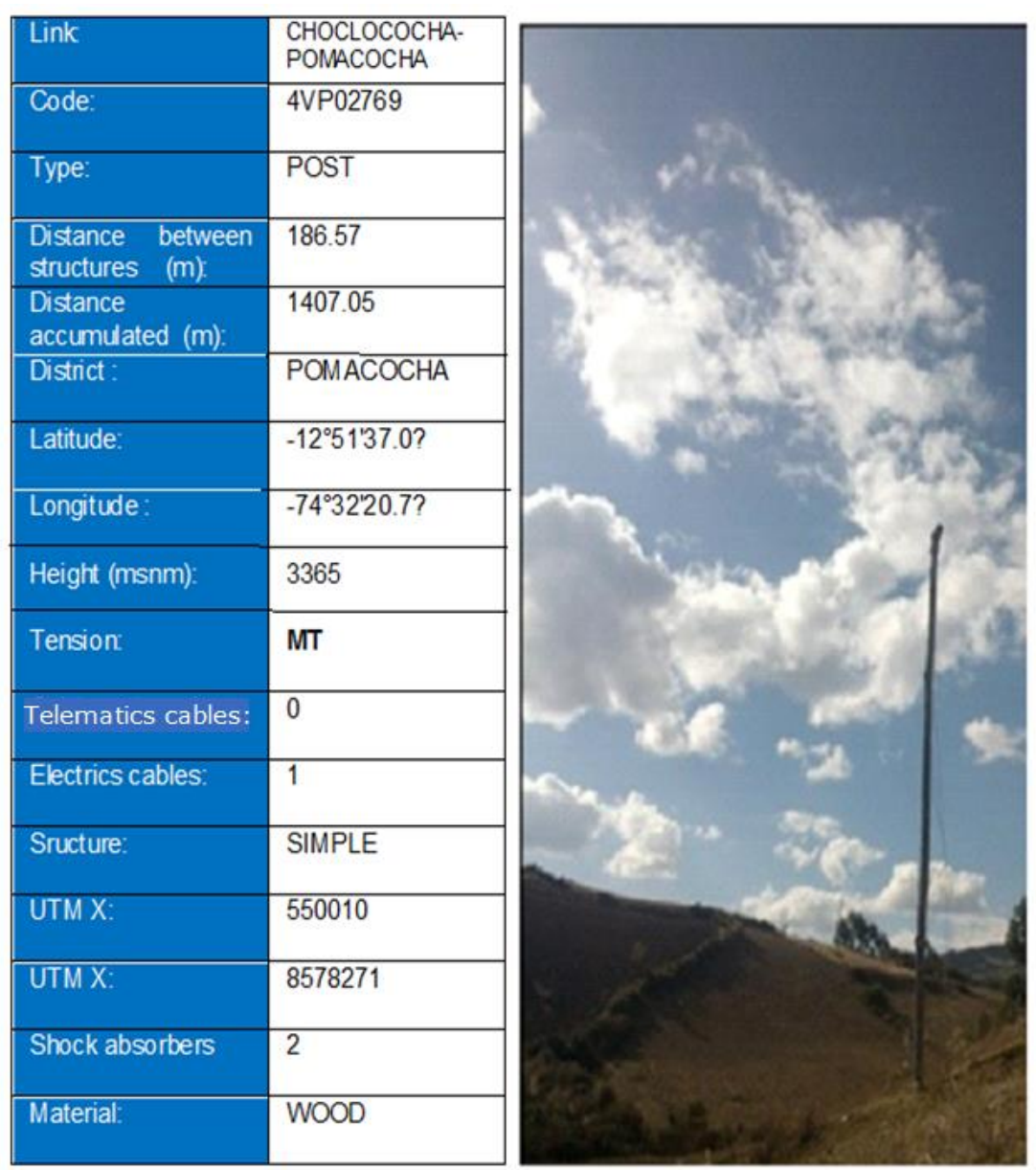

Figure 2. Characteristics and photograph of the structure: post 8 , medium voltage Table 1. Optical cable selection according to span

\begin{tabular}{|c|c|}
\hline Span range (m) & $\begin{array}{c}\text { Maximum cable } \\
\text { span ADSS (m) }\end{array}$ \\
\hline$<=200$ & 200 \\
\hline 200 a 300 & 300 \\
\hline 300 a 400 & 400 \\
\hline 400 a 600 & 600 \\
\hline$>600$ & 1000 \\
\hline
\end{tabular}

Table 2. Selection of fittings according to span

\begin{tabular}{|c|c|c|}
\hline $\begin{array}{c}\text { Suspension } \\
\text { fitting }\end{array}$ & $\begin{array}{c}\text { Retaining } \\
\text { hardware }\end{array}$ & Maximum span \\
\hline S1 & R1 & Hasta $110 \mathrm{~m}$ \\
\hline S2 & R2 & 100 a $220 \mathrm{~m}$ \\
\hline S3 & R3 & 200 a $330 \mathrm{~m}$ \\
\hline S4 & R4 & 300 a $440 \mathrm{~m}$ \\
\hline S5 & R5 & 400 a $660 \mathrm{~m}$ \\
\hline S6 & R6 & 600 a $1000 \mathrm{~m}$ \\
\hline
\end{tabular}

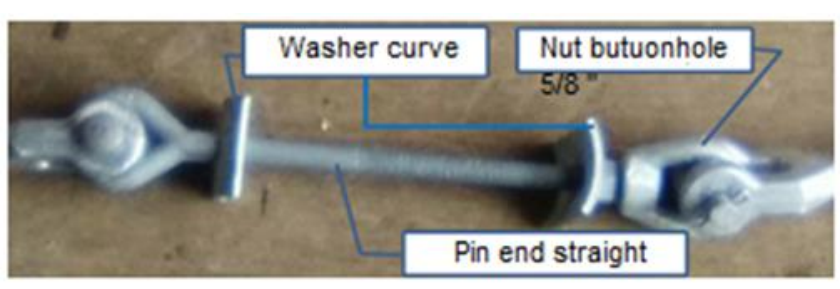




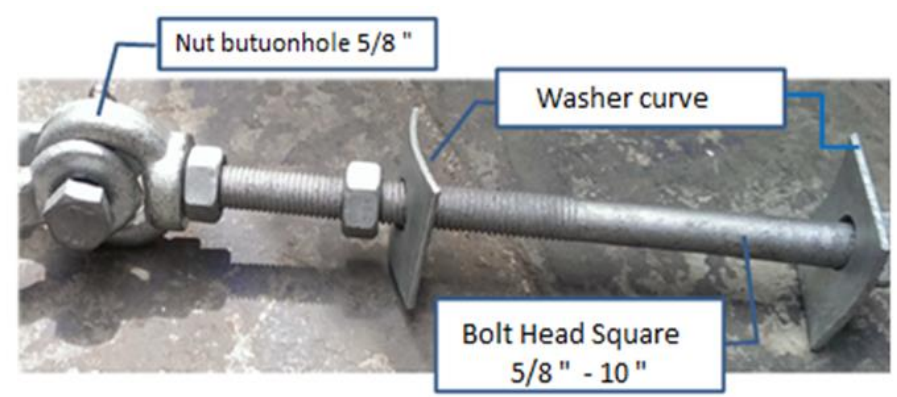

Figura 3. Suspension (top) and retaining (bottom) hardware for new posts [9]

The recommended ADSS cable reserve lengths along the route depend on whether the area is urban or not and whether it is close to a start or end node or a junction box. In Table 3, details for determining the cable reserve lengths are given. For the current case, only one splice is required since the area is rural. The minimum distances between power lines and optical cables are given in Table 4. The maximum sag selection of the optical cable is given in percentage with respect to the length of the spans, as shown in Table 5. Optical cables, with aerial laying between poles, tend to move or oscillate due to the force of the wind which, added to the expansions and compressions due to temperature, can affect the propagation of the optical signal through the cable due to the phenomenon of polarization mode dispersion [6]. For this purpose, dampers are installed to mitigate cable oscillations. Table 6 shows the number of dampers required depending on the distance between poles $[7,8]$.

Table 3. Recommended optical cable backup lengths [8].

\begin{tabular}{|l|l|}
\hline Case & Reserve (m) \\
\hline Urban Zone, each $500 \mathrm{~m}$ & 40 \\
\hline Rural Zone, each 1000 to $1500 \mathrm{~m}$ & 40 \\
\hline Route start & 40 \\
\hline Route end & 40 \\
\hline Junction box & 40 \\
\hline
\end{tabular}

With the field information and the ADSS cable laying standards, the requirements, specifications and metering to be used in the ADSS cable laying between the towns of Choclococha and Pomacocha using 5KV MV poles [9] were elaborated. In the Results section, the required fittings are presented according to different cases along the route.

Table 4. Safety distances between power cables and fiber optic cables [8].

\begin{tabular}{|l|l|}
\hline Case or supply voltage & Vertical safety distance \\
\hline $\begin{array}{l}\text { Conductor, hardware and equipment support, } \\
\text { messenger cable and grounded support }\end{array}$ & $0.60 \mathrm{~m}$ \\
\hline Up to 23 23 KV & $1.80 \mathrm{~m}$ \\
\hline More than KV & $1.8 \mathrm{~m}$ more than $0.01 \mathrm{~m}$ for KV (over $23 \mathrm{KV}$ ) \\
\hline
\end{tabular}

Table 5. Maximum optical cable deflection

\begin{tabular}{|c|c|}
\hline $\begin{array}{c}\text { Maximum sag } \\
\text { (\% of optical cable length) }\end{array}$ & Permitted span \\
\hline $1 \%$ & 0 a $400 \mathrm{~m}$ \\
\hline $2 \%$ & 401 a $800 \mathrm{~m}$ \\
\hline $3 \%$ & 801 a $1000 \mathrm{~m}$ \\
\hline $5 \%$ & $>1000 \mathrm{~m}$ \\
\hline
\end{tabular}

Source: FITEL (2014)

Table 6. Types of fittings to be installed in ADSS cable installation

\begin{tabular}{|c|c|}
\hline Case & Hardware required \\
\hline Uniform span & Three suspension fittings followed by one retaining fitting \\
\hline Route deviation, greater than $20^{\circ}$. & Retainer \\
\hline Inicio de ruta & Retainer \\
\hline Route end & Retainer \\
\hline Type of span and/or angle & Suspension hardware: S1, S2, S3, S4, S5, S6 \\
\hline Type of span & Retainer: R1, R2, R3, R4, R5, R6 \\
\hline Junction box & Retainer \\
\hline Adjacent poles & Retention \\
\hline Shock absorbers & $2,4,6$ or 8 (according to recommendations) \\
\hline
\end{tabular}




\begin{tabular}{|l|l|}
\hline Posts & Braces or reins (as needed) \\
\hline Route deviation & Messenger (as needed) \\
\hline
\end{tabular}

\subsection{Transport network - optical power budget}

The optical power budget was determined by means of an interactive software application (see Results section) developed using Matlab and its GUIDE graphical programming environment. This application allowed the simulation and calculation of the power budget of the single-mode optical link between the Pomacocha and Choclococha nodes; the following variables and parameters were taken into account following a standardized procedure [10].

- Number and loss per pair of connectors

Only two pairs of connectors are considered (one pair at each end of the cable) since it is a point-to-point link. According to the IEC 61300-3-7 standard, $0.5 \mathrm{~dB}$ is taken as maximum loss per connector pair [11].

- Number and loss of fusion splices

The span between the two nodes consists of three splices. Two at the ends (ADSS cable fused with pigtails) and one at pole 10, straight splice. The maximum loss per splice, according to IEC 61300-3-7 standard is 0.1dB [11].

- Fiber optic cable runs length

The span length between the two nodes is 2816 meters.

- Working wavelength

Optical fiber works with a $1550 \mathrm{~nm}$ wave, which is the length used for long-range trunk sections due to its low losses.

- Losses per kilometer of optical fiber at $1550 \mathrm{~nm}$

According to the IEC60793-2-50 standard, losses per kilometer should be a maximum of 0.25dB/km [11].

- Minimum and maximum transmitter power

This information is obtained from the transceivers to which the two wires (transmitter and receiver) that make up the link between the two nodes are connected. The transmitter output power is $2 \mathrm{~dB}$. However, it can vary between -4.7 and $4 \mathrm{dBm}$. For the simulations with the application, the extreme values are considered.

- Receiver sensitivity and maximum power

These values are also obtained from the technical characteristics of the transceiver. The receiver works with an average power of $-5.81 \mathrm{~dB}$. However, it can receive between -1 and $-15.8 \mathrm{dBm}$. This last value is its sensitivity or minimum power that it can receive and interpret correctly.

- Total power penalty

It consists of two parts. The first is the power penalty, given by the equipment manufacturer, typically $2 \mathrm{~dB}$. The second is the repair margin, typically two splices of $0.3 \mathrm{~dB}$ each are considered; it gives a total of $0.6 \mathrm{~dB}$. The sum of the previous results becomes the total power penalty $(2.6 \mathrm{~dB})$.

The output variables are as follows (at $1550 \mathrm{~nm}$ ):

- Total attenuation of the cabling system.

This is the sum of losses due to connectors, splices and the fiber itself.

- Two connectors, the maximum losses are $0.5 \mathrm{~dB} \times 2=1 \mathrm{~dB}$

- Three splices, maximum losses of $0.1 \mathrm{~dB} \times 3=0.3 \mathrm{~dB}$

- 2915 meters of optical fiber (including reserves), maximum losses are $0.25 \mathrm{~dB} \times 2.915 \mathrm{~km}=0.729 \mathrm{~dB}$

Then, the total attenuation of the cabling system is: $(1+0.3+0.729) \mathrm{dB}=2.029 \mathrm{~dB}$

- System gain

It is the difference between the transmitter power and the sensitivity or minimum receive power. Two situations are considered:

- With maximum transmit power.

System gain $=4 \mathrm{dBm}-(-15.8 \mathrm{dBm})=19.8 \mathrm{~dB}$

- With minimum transmit power

System gain $=-4.7 \mathrm{dBm}-(-15.8 \mathrm{dBm})=11.1 \mathrm{~dB}$

- Total loss budget per link

It is calculated as the difference between the system gain and the total power penalty. There are also two

extreme cases depending on the transmitter power.

- With maximum transmit power

Total loss budget per link $=19.8 \mathrm{~dB}-2.6 \mathrm{~dB}=17.2 \mathrm{~dB}$

- With minimum transmit power

Total loss budget per link $=11.1 \mathrm{~dB}-(2.6 \mathrm{~dB})=8.5 \mathrm{~dB}$

- System performance margin

Calculated as the difference between the total link loss budget and the total attenuation of the cabling system.

According to the transmitter power, we have two extreme cases:

- With maximum transmit power

System performance margin $=17.2 \mathrm{~dB}-2.029 \mathrm{~dB}=15.171 \mathrm{~dB}$ 
- With minimum transmit power

System performance margin $=8.5 \mathrm{~dB}-(2.029 \mathrm{~dB})=6.471 \mathrm{~dB}$

The optical power budget was calculated for the two extreme scenarios:

(a) Transmitter at maximum power, a signal of $2.17 \mathrm{dBm}$ is obtained on the receiving side.

b) Transmitter at minimum power, a signal of $-6.53 \mathrm{dBm}$ is obtained on the receiving side.

\subsection{Access network}

The access network consists of point-to-multipoint radio links, in the unlicensed $5.8 \mathrm{GHz}$ band, radiating from the node in Choclococha to the entire surrounding area. The design of the radiating system was carried out using LINKPlanner software [12]. Likewise, the various equipment and antennas are from the same manufacturer. The objective of the design is to model the wireless coverage in the entire geographical area of the town of Choclococha. Likewise, the software recommends and allows the selection of the most appropriate equipment and antennas according to the information entered, as well as the radiation power, range, coverage angles and inclination, among others.

The design process with LINKPlanner starts by defining the radio node with its geographic coordinates and name. Then, in that node, a HUB is defined, which is the concentration of one or more Access Points that will radiate through sectorial antennas $\left(90^{\circ}\right.$ or $120^{\circ}$ maximum each) to the entire population of Choclococha. Next, the Access Points are configured (Table 7), four in total, with which $100 \%$ coverage is achieved (see Figure 4). Each Access Point covers a certain sector of the district, with a certain range, and consists of a PMP sector antenna and a $5.8 \mathrm{GHz}$ free band transmitter/receiver radio. All Access Point radios are Cambium Networks [12] model PMP450i, 20MHz/channel and 45dBm EIRP, are manufactured with metal casing and are IP66 and IP67 compliant for harsh environments, supporting data rates up to 300Mbps with channels up to 40MHz. These radios have 100/1000BaseT interface and work with IPv4, IPv6, UDP, TCP/IP, ICMP, HTTP and FTP protocols. They also support various network management protocols. Each radio and antenna can serve up to 238 users. They can work with various digital modulations (QPSK, 16QAM, 64QAM, 256QAM). The PMP 450i radios have latencies in the order of 3 to $5 \mathrm{~ms}$. Their maximum range is $64 \mathrm{~km} \mathrm{[12].}$

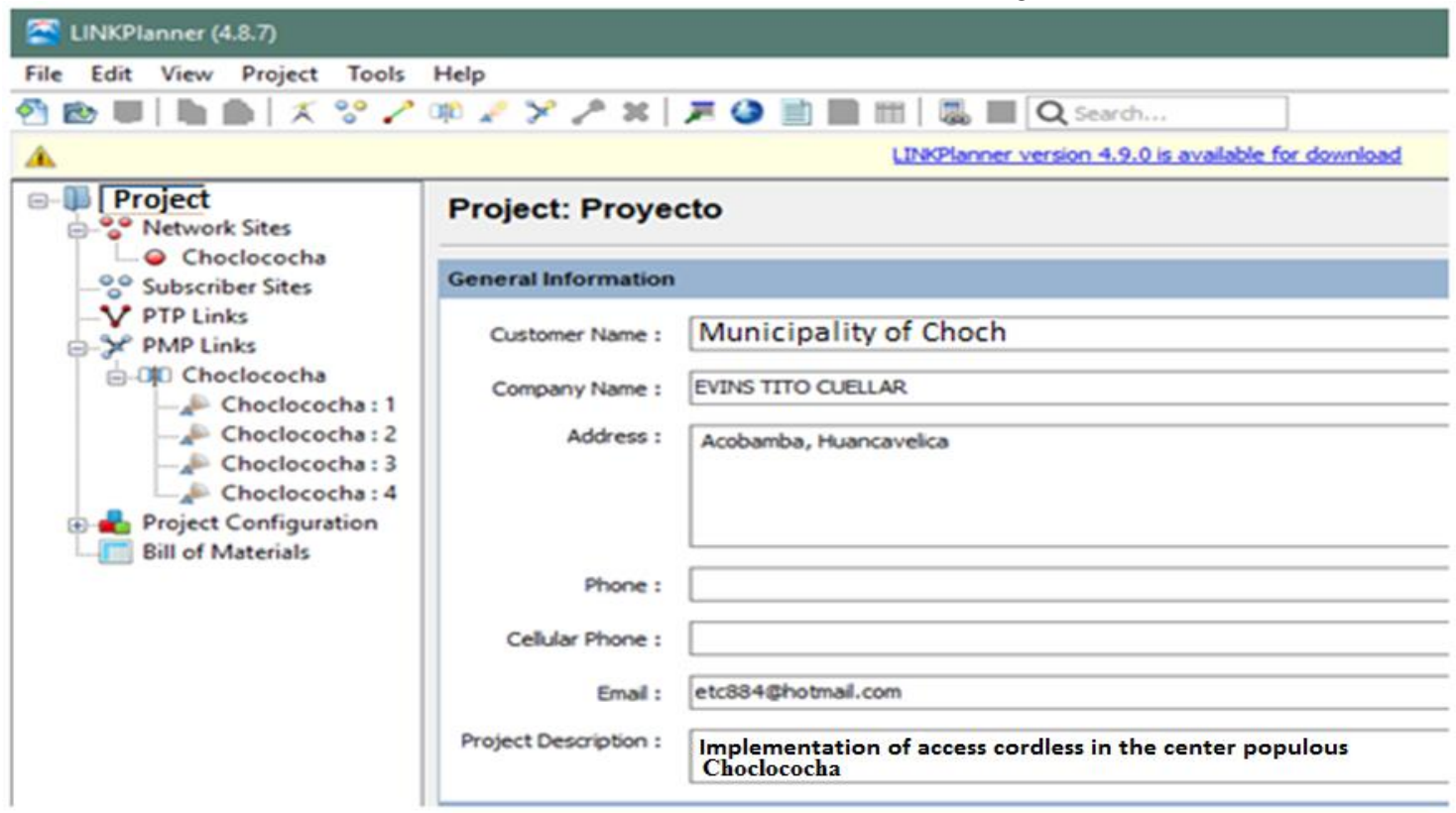

Figure 4. Definition of a hub located at the radio node and with four Access Points. Source: Own elaboration

Table 7. Definition of Access Points

\begin{tabular}{lllll}
\hline $\begin{array}{l}\text { Access Point } \\
\text { Name }\end{array}$ & Product & $\begin{array}{c}\text { Antenna } \\
\text { Azimuth }\end{array}$ & Beamwidth & Band \\
\hline $\begin{array}{l}\text { Choclococha } \\
: 1\end{array}$ & PMP450i & $15.0^{\circ}$ & $90.0^{\circ}$ & $5.8 \mathrm{GHz}$ \\
\hline $\begin{array}{l}\text { Choclococha } \\
: 2\end{array}$ & PMP450i & $90.0^{\circ}$ & $60.0^{\circ}$ & $5.8 \mathrm{GHz}$ \\
\hline $\begin{array}{l}\text { Choclococha } \\
: 3\end{array}$ & PMP450i & $200.0^{\circ}$ & $120.0^{\circ}$ & $5.8 \mathrm{GHz}$ \\
\hline $\begin{array}{l}\text { Choclococha } \\
: 4\end{array}$ & PMP450i & $300.0^{\circ}$ & $60.0^{\circ}$ & $5.8 \mathrm{GHz}$ \\
\hline
\end{tabular}

Source: Own elaboration 


\section{Results and discussion}

The experimental data and results obtained in this work are presented below.

Conveyor network - outside plant

Figure 5 shows the route of the optical cable. It consists of 23 poles: 18 medium voltage poles (shown in blue) and 5 new poles (shown in yellow). Pole 1 is located in Choclococha and pole 23 in Pomacocha.

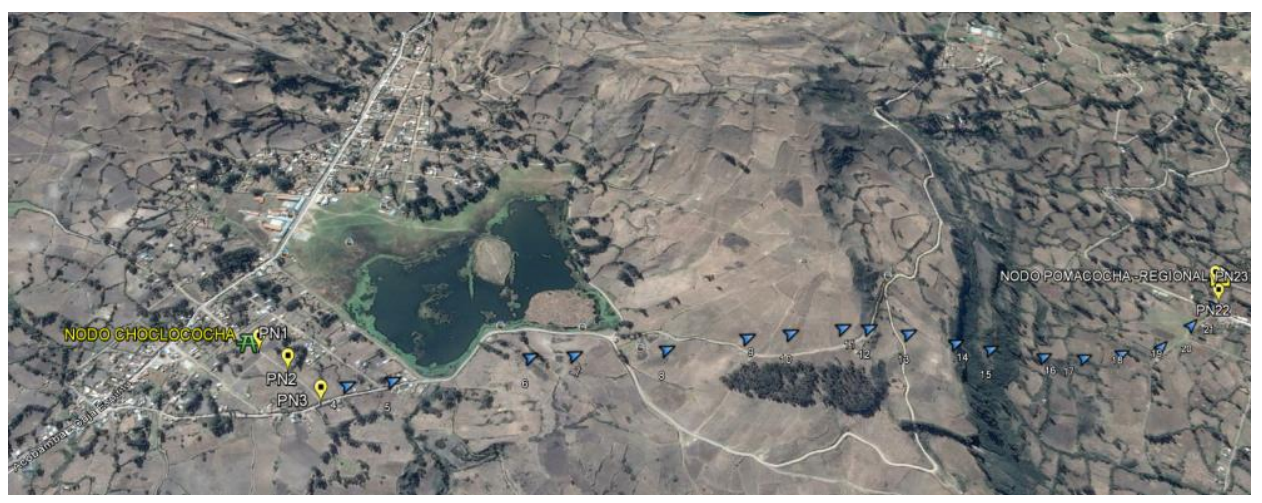

Figure 5. Fiber route between the Pomacocha mode and the node to be located in Choclococha.

Source: Own elaboration

Table 8 and Table 9 show the results of the optical cable laying design. Table 8 shows the results related to the optical cable: length of the cable between poles, distance between poles, deflection of the cable, coil used. Also, it is specified whether the pole is existing or new and its electrical voltage level in service. This table is important because it allows sizing the number of coils and fiber to be used. Table 9 shows aspects related to the hardware; also, the material of the pole (concrete or wood); position and length of reserve cable; types, quantity and location of splices; quantity and location of retention, suspension and support hardware used; height of the cable above ground level and, finally, quantity and location of shock absorbers used.

Table 8. Specifications for laying ADSS optical cable between poles

\begin{tabular}{|c|c|c|c|c|c|c|}
\hline ITEM & $\begin{array}{c}\text { Structure } \\
\text { and stress } \\
\text { level }\end{array}$ & $\begin{array}{l}\text { Distance } \\
\text { between } \\
\text { elements } \\
\end{array}$ & Arrow & Span & $\begin{array}{l}\text { Fiber optic } \\
\text { coil ID }\end{array}$ & $\begin{array}{l}\text { Structure } \\
\text { height (m) }\end{array}$ \\
\hline $\begin{array}{c}\text { Choclococha } \\
\text { Node }\end{array}$ & Node & 50.00 & 0.30 & 300 & 306-300 HNC & 0 \\
\hline 1 & Post & 93.29 & 1.90 & 300 & 306-300 HNC & 12 \\
\hline 2 & Post & 79.21 & 0.40 & 300 & 306-300 HNC & 12 \\
\hline 3 & Post & 123.30 & 1.24 & 300 & 306-300 HNC & 12 \\
\hline 4 & Post $5 \mathrm{KV}$ & 64.24 & 0.50 & 300 & 306-300 HNC & 11 \\
\hline 5 & Post 5KV & 312.89 & 4.69 & 300 & 306-300 HNC & 11 \\
\hline 6 & Post 5KV & 101.20 & 1.01 & 300 & 306-300 HNC & 11 \\
\hline 9 & Post 5KV & 211.36 & 2.64 & 300 & 306-300 HNC & 11 \\
\hline 10 & Post 5KV & 186.57 & 1.87 & 200 & 206-200 HNC & 11 \\
\hline 11 & Post 5KV & 100.23 & 1.00 & 200 & 206-200 HNC & 11 \\
\hline 12 & Post 5KV & 122.16 & 1.22 & 200 & 206-200 HNC & 11 \\
\hline 13 & Post 5KV & 61.59 & 0.31 & 200 & 206-200 HNC & 11 \\
\hline 14 & Post 5KV & 101.87 & 1.02 & 200 & 206-200 HNC & 11 \\
\hline 15 & Post 5KV & 127.76 & 1.28 & 200 & 206-200 HNC & 11 \\
\hline 16 & Post 5KV & 106.47 & 1.06 & 200 & 206-200 HNC & 11 \\
\hline 17 & Post 5KV & 162.70 & 1.63 & 200 & 206-200 HNC & 11 \\
\hline 18 & Post 5KV & 120.86 & 1.21 & 200 & 206-200 HNC & 11 \\
\hline 19 & Post 5KV & 103.66 & 1.04 & 200 & 206-200 HNC & 11 \\
\hline 20 & Post 5KV & 107.09 & 1.07 & 200 & 206-200 HNC & 11 \\
\hline 21 & Post 5KV & 123.56 & 1.24 & 200 & 206-200 HNC & 11 \\
\hline 22 & Post 5KV & 100.34 & 1.00 & 200 & 206-200 HNC & 11 \\
\hline
\end{tabular}




\begin{tabular}{|c|c|c|c|c|c|c|}
\hline 21 & Post 5KV & 52.51 & 0.26 & 200 & $206-200 \mathrm{HNC}$ & 11 \\
\hline 22 & Post & 40.82 & 0.44 & 200 & $206-200 \mathrm{HNC}$ & 12 \\
\hline 23 & Post & 62.49 & 0.48 & 200 & $206-200 \mathrm{HNC}$ & 12 \\
\hline $\begin{array}{c}\text { Pomacocha } \\
\text { Node }\end{array}$ & NODE & 50.35 & 0.49 & 200 & $206-200 \mathrm{HNC}$ & 0 \\
\hline
\end{tabular}

Source: Own elaboration

Figure 6 shows the single-line diagram of the optical link between the nodes located in Pomacocha and Choclococha. This diagram shows the cable mileage required, as well as the location and type of splices along the route, the nodes, the sections, the spans per section, the partial and total mileages. Thus, the optical link between the nodes requires an optical fiber cable run of $2915.81 \mathrm{~m}$ and consists of two sections with a straight splice box located $1222 \mathrm{~m}$ from the Choclococha node.

Table 9. Specifications of the hardware to be used for ADSS optical cable installation

\begin{tabular}{|c|c|c|c|c|c|c|}
\hline ITEM & $\begin{array}{c}\text { Reserve } \\
\text { (m) }\end{array}$ & Fittings & $\begin{array}{l}\text { Retention } \\
\text { fittings }\end{array}$ & $\begin{array}{c}\text { Suspension } \\
\text { fittings }\end{array}$ & $\begin{array}{c}\text { Support } \\
\text { fittings }\end{array}$ & Shock absorber \\
\hline $\begin{array}{l}\text { Choclo- } \\
\text { cocha } \\
\text { NODE }\end{array}$ & 0 & 0 & NODE & & NODE & 0 \\
\hline 1 & & & & S2 & SS & 0 \\
\hline 2 & & & $\mathrm{R} 2$ & & SR & 0 \\
\hline 3 & & & & S2 & SS & 0 \\
\hline 4 & & & & S2 & SS & 0 \\
\hline 5 & & & & S3 & SS & 4 \\
\hline 6 & & & & S3 & SS & 2 \\
\hline 9 & & & & S3 & SS & 4 \\
\hline 10 & 50 & STRAIGHT & R3 & & SR & 2 \\
\hline 11 & & & & S2 & SS & 2 \\
\hline 12 & & & & S2 & SS & 2 \\
\hline 13 & & & & S2 & SS & 0 \\
\hline 14 & & & & $\mathrm{~S} 2$ & SS & 2 \\
\hline 15 & & & & S2 & SS & 2 \\
\hline 16 & & & R2 & & SR & 2 \\
\hline 17 & & & & S2 & SS & 2 \\
\hline 18 & & & & S2 & SS & 2 \\
\hline 19 & & & & S2 & SS & 2 \\
\hline 20 & & & & S2 & SS & 2 \\
\hline 21 & & & R2 & & SR & 2 \\
\hline 22 & & & & S2 & SS & 2 \\
\hline 21 & & & $\mathrm{R} 2$ & & SR & 0 \\
\hline 22 & & & R1 & & SR & 0 \\
\hline 23 & & & & S1 & SS & 0 \\
\hline $\begin{array}{l}\text { Poma- } \\
\text { cocha } \\
\text { NODE }\end{array}$ & 0 & 0 & 0 & 0 & 0 & 0 \\
\hline
\end{tabular}

Source: Own elaboration 


\section{Distance from the tour: $2766.52 \mathrm{~m}$}

\section{Optical fiber ADSS, 48 threads, $2915.81 \mathrm{~m}$}

(Includes: dates and reserves)

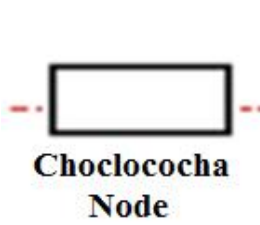

Reserves: $40 \mathrm{~m}$

\section{SPAN 300}

\section{$1222.06 \mathrm{~m}$}

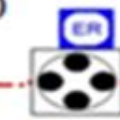

Post 10

Straight splicing

Reserves: $40 \mathrm{~m}$
SPAN 200

$1544.46 \mathrm{~m}$

Figure 6. One-line diagram of the conveying network

Source: Own elaboration

\section{1}

\subsection{1 Transmission network - optical power Budget}

The calculation of the power budget is an essential part of the design of an optical trunk. The results of the design procedure followed according to the steps and recommendations detailed in the Methodology section are shown below. Figure 7 shows the transmit and receive power data of the fiber optic transceivers at the routers of both nodes, with ranges of $40 \mathrm{~km}$. Figure 8 shows the results of the optical power budget calculation. The first result $(2,196 \mathrm{dBm})$ exceeds the maximum allowed by the receiver $(-1 \mathrm{dBm})$. Therefore, the maximum transmitted power should be reduced to avoid receiver saturation or damage. The maximum transmitted power should be $0.804 \mathrm{dBm}$, value with which a reception power of $-1 \mathrm{dBm}$ is achieved, which is, precisely, the limit value allowed by the receiver. The second result $(-6.503 \mathrm{dBm})$ is above the minimum recognizable $(-15.8 \mathrm{dBm})$ by the receiver.

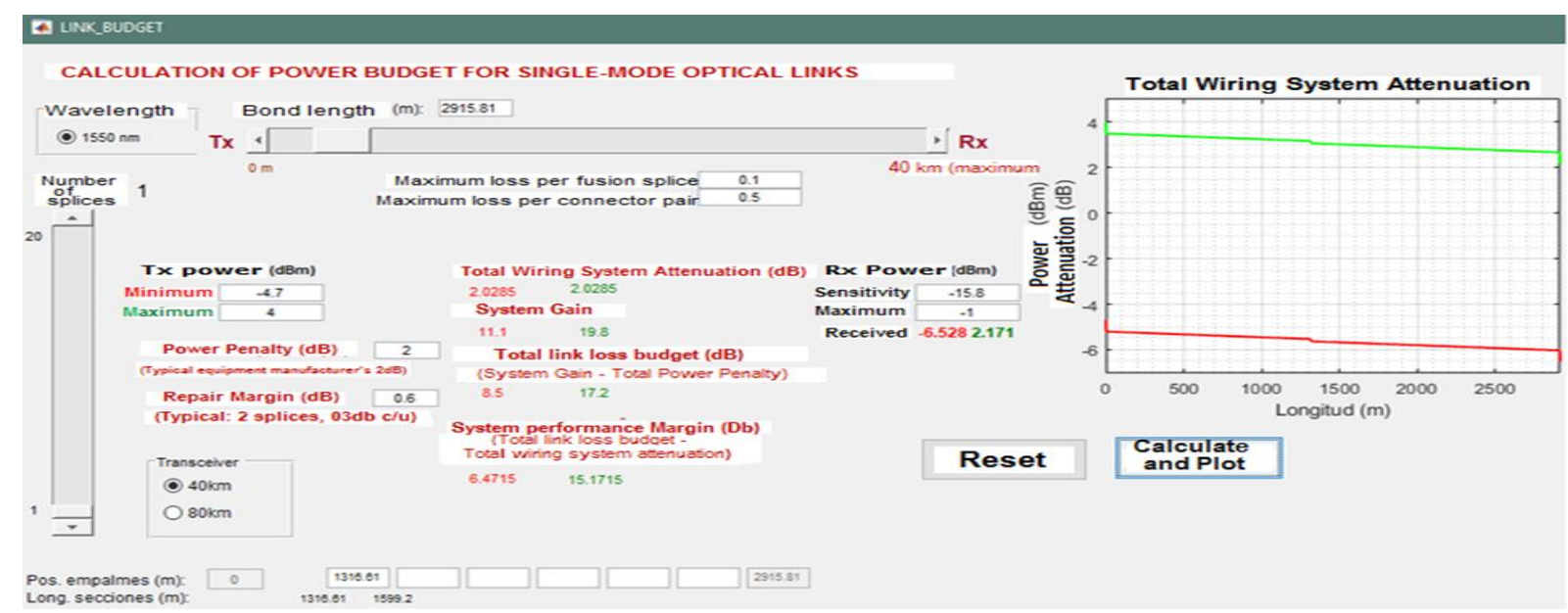

Figure 7. Fiber optic transceiver data, including transmit and receive powers, also the working wavelength [8].

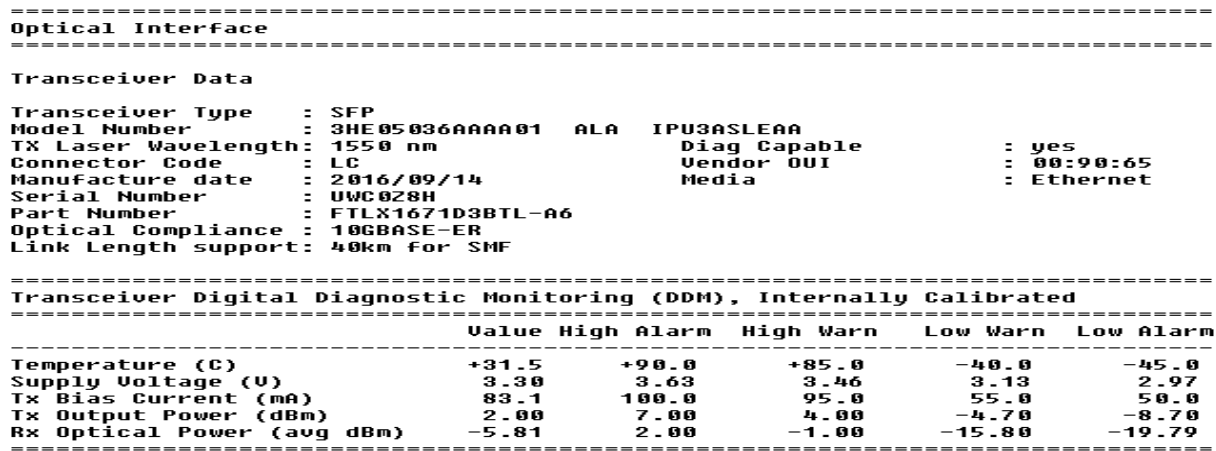

Figure $\overline{\mathbf{8}}$. Power budget calculated by means of an application developed in Matlab Source: Own elaboration 


\section{Access network}

The subscriber radios selected by the LINKPlanner software, shown in Figure 9, left, work in the $5.8 \mathrm{GHz}$ band. They are made of metal; comply with IP66 and IP67 standards for harsh environments. They operate at up to $300 \mathrm{Mbps}$ per sector on $40 \mathrm{MHz}$ channels. Regarding power, the antenna gain is $23 \mathrm{dBi}$, the maximum output power of the radio is $28 \mathrm{dBm}$ and the maximum EIRP is $50 \mathrm{dBm}$, with ranges up to $64 \mathrm{~km}$.

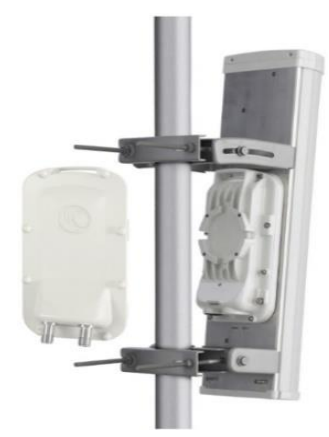

Figure 9. Subscriber module (left) and Access Point with sectorial antenna (right) [12].

Figure 10 shows the results of the coverage simulation performed with the LINKPlanner software. The simulator is integrated with Google Maps showing the coverage on the same map of the town of Choclococha. The red dot is the radio node where the four Access Points and the sectorial antennas are located (one of these antennas is shown in Figure 9, right). According to Figure 10, the entire population of interest is covered.

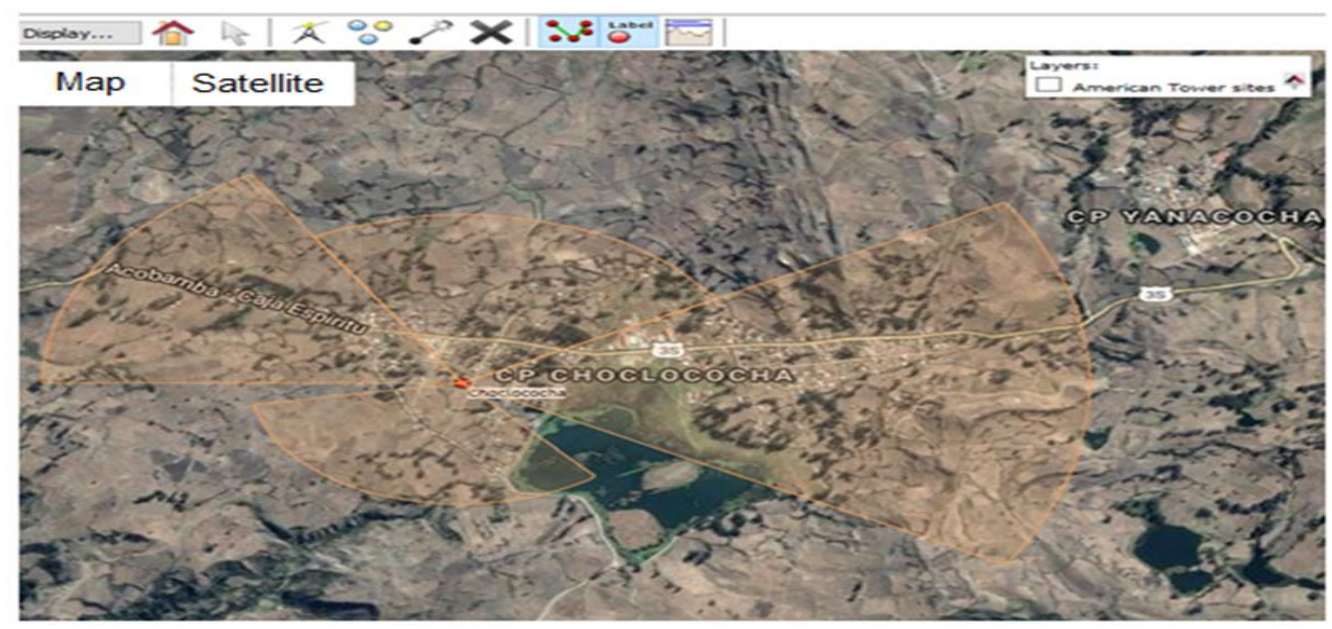

Figure 10. Coverage in the town center of Choclococha with four Access Points and their respective before sectorial

\section{Source: Own elaboration}

Table 10 shows the results of the wireless reception power level measurements (downlink RSSI) measured in a sample of 60 homes using the service. The table also includes information on coordinates and altitude at each 
measurement point. The results of these measurements were used to verify compliance with the expected values according to the manufacturer's specifications of the wireless subscriber equipment.

Table 10. Measurements of wireless reception levels

\begin{tabular}{|c|c|c|c|c|}
\hline Measurement & South latitude & West longitude & $\begin{array}{l}\text { Height above sea } \\
\text { level (m) }\end{array}$ & $\begin{array}{c}\text { Receiving power } \\
\text { (down link RSSI, dBm) }\end{array}$ \\
\hline 1 & $12^{\circ} 28^{\prime} 3.8^{\prime \prime}$ & $74^{\circ} 46^{\prime} 3.15^{\prime \prime}$ & 2701 & -78 \\
\hline 2 & $12^{\circ} 28^{\prime} 4.4^{\prime \prime}$ & $74^{\circ} 46^{\prime} 3.13^{\prime \prime}$ & 2695 & -77 \\
\hline 3 & $12^{\circ} 28^{\prime} 5.18^{\prime \prime}$ & $74^{\circ} 46^{\prime} 3.12^{\prime \prime}$ & 2690 & -75 \\
\hline 4 & $12^{\circ} 28^{\prime} 5.73^{\prime \prime}$ & $74^{\circ} 46^{\prime} 23.1^{\prime \prime}$ & 2688 & -76 \\
\hline 5 & $12^{\circ} 28^{\prime} 6.15^{\prime \prime}$ & $74^{\circ} 46^{\prime} 0.97^{\prime \prime}$ & 2698 & -75 \\
\hline 6 & $12^{\circ} 28^{\prime} 6.35^{\prime \prime}$ & $74^{\circ} 46^{\prime} 20.32^{\prime \prime}$ & 2699 & -74 \\
\hline 7 & $12^{\circ} 28^{\prime} 6.67^{\prime \prime}$ & $74^{\circ} 46^{\prime} 19.34^{\prime \prime}$ & 2700 & -74 \\
\hline 8 & $12^{\circ} 28^{\prime} 7.3^{\prime \prime}$ & $74^{\circ} 46^{\prime} 18.83^{\prime \prime}$ & 2701 & -72 \\
\hline 9 & $12^{\circ} 28^{\prime} 8.23^{\prime \prime}$ & $74^{\circ} 46^{\prime} 18.74^{\prime \prime}$ & 2700 & -71 \\
\hline 10 & $12^{\circ} 28^{\prime} 9.1^{\prime \prime}$ & $74^{\circ} 46^{\prime} 18.63^{\prime \prime}$ & 2691 & -69 \\
\hline 11 & $12^{\circ} 28^{\prime} 9.61^{\prime \prime}$ & $74^{\circ} 46^{\prime} 18.54^{\prime \prime}$ & 2689 & -68 \\
\hline 12 & $12^{\circ} 28^{\prime} 10.12^{\prime \prime}$ & $74^{\circ} 46^{\prime} 18.14^{\prime \prime}$ & 2690 & -69 \\
\hline 13 & $12^{\circ} 28^{\prime} 11.34^{\prime \prime}$ & $74^{\circ} 46^{\prime} 17.93^{\prime \prime}$ & 2694 & -70 \\
\hline 14 & $12^{\circ} 28^{\prime} 11.98^{\prime \prime}$ & $74^{\circ} 46^{\prime} 17.48^{\prime \prime}$ & 2683 & -66 \\
\hline 15 & $12^{\circ} 28^{\prime} 12.21^{\prime \prime}$ & $74^{\circ} 46^{\prime} 16.42^{\prime \prime}$ & 2688 & -65 \\
\hline 16 & $12^{\circ} 28^{\prime} 12.83^{\prime \prime}$ & $74^{\circ} 46^{\prime} 16.91^{\prime \prime}$ & 2692 & -66 \\
\hline 17 & $12^{\circ} 28^{\prime} 13.39^{\prime \prime}$ & $74^{\circ} 46^{\prime} 15.39^{\prime \prime}$ & 2689 & -62 \\
\hline 18 & $12^{\circ} 28^{\prime} 13.52^{\prime \prime}$ & $74^{\circ} 46^{\prime} 15.11^{\prime \prime}$ & 2690 & -63 \\
\hline 19 & $12^{\circ} 28^{\prime} 13.71^{\prime \prime}$ & $74^{\circ} 46^{\prime} 14.93^{\prime \prime}$ & 2687 & -62 \\
\hline 20 & $12^{\circ} 28^{\prime} 12.91^{\prime \prime}$ & $74^{\circ} 46^{\prime} 14.38^{\prime \prime}$ & 2694 & -60 \\
\hline 21 & $12^{\circ} 28^{\prime} 12.62^{\prime \prime}$ & $74^{\circ} 46^{\prime} 13.12^{\prime \prime}$ & 2691 & -60 \\
\hline 22 & $12^{\circ} 28^{\prime} 13.23^{\prime \prime}$ & $74^{\circ} 46^{\prime} 12.65^{\prime \prime}$ & 2689 & -59 \\
\hline 23 & $12^{\circ} 28^{\prime} 13.91^{\prime \prime}$ & $74^{\circ} 46^{\prime} 11.58^{\prime \prime}$ & 2701 & -58 \\
\hline 24 & $12^{\circ} 28^{\prime} 14.65^{\prime \prime}$ & $74^{\circ} 46^{\prime} 10.48^{\prime \prime}$ & 2698 & -59 \\
\hline 25 & $12^{\circ} 28^{\prime} 16.32^{\prime \prime}$ & $74^{\circ} 46^{\prime} 10.21^{\prime \prime}$ & 2688 & -58 \\
\hline 26 & $12^{\circ} 28^{\prime} 19.08^{\prime \prime}$ & $74^{\circ} 46^{\prime} 9.73^{\prime \prime}$ & 2686 & -59 \\
\hline 27 & $12^{\circ} 28^{\prime} 17.56^{\prime \prime}$ & $74^{\circ} 46^{\prime} 7.27^{\prime \prime}$ & 2697 & -55 \\
\hline 28 & $12^{\circ} 28^{\prime} 18.51^{\prime \prime}$ & $74^{\circ} 46^{\prime} 7.27^{\prime \prime}$ & 2697 & -56 \\
\hline 60 & $12^{\circ} 28^{\prime} 28.47^{\prime \prime}$ & $74^{\circ} 45^{\prime} 59.56^{\prime \prime}$ & 2674 & -73 \\
\hline
\end{tabular}

Source: Author's elaboration

Taking the results of receiving power measurements, contained in Table 10, two statistics, average and standard deviation, were calculated.

$\mathrm{x} \square=-63.9 \mathrm{dBm}$ Average of receive power measurements

$\sigma=8 \mathrm{dBm}$ Standard deviation of receive power measurements.

$\mu \_0=-86 \mathrm{dBm}$ Expected mean value

For a significance level of $\alpha=0.1$, or confidence level of 0.9 , the confidence interval was determined by the following formula:

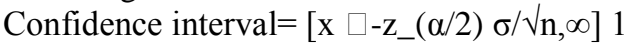

Where: 
n Sample size (60)

z_ $\alpha$ Statistic, critical value, its value is 1.645 for $\alpha=0.1$ or confidence level of 0.9 .

$z_{-}(\alpha / 2)$ Its value is 1.96 for $\alpha / 2=0.05$ or confidence level of 0.95 .

The values were replaced, obtaining the following confidence interval:

Confidence interval $=[-86-1.968 .0 / \sqrt{ } 60, \infty] 2$

Confidence interval $=[-88.02, \infty] 3$

Table 11 shows the results of the speed measurements, both upstream and downstream, measured on a sample of 60 service users. The results of these measurements were used to verify compliance with the expected values. To this end, the acceptance zone was determined as detailed below.

DOWN

For a significance level of $\alpha=0.1$ (90\% confidence level), the acceptance interval was determined by the following formula:

Acceptance interval $=\left[\mu \_0-z_{-}(\alpha / 2) \sigma / \sqrt{ } \mathrm{n}, \infty\right] 4$

Where:

n Sample size (60)

$\mathrm{z} \_\alpha$ Statistic, critical value, its value is 1.65 for $\alpha=0.1$ or $90 \%$ confidence level (1.65).

$90 \%$ confidence level (1.65)

z_( $\alpha / 2)$ Equal to $0.1 / 2=0.05$, corresponds to a confidence level of 1.96 .

Replacing the values:

Acceptance interval $=[819.2-1.963 .5 / \sqrt{ } 60, \infty] 5$

Acceptance interval $=[818.32, \infty] 6$

RISE

Determination of the acceptance zone.

For a significance level of $\alpha=0.1$ or confidence level of 0.9 , the acceptance interval was determined by the following formula:

Acceptance interval $=\left[\mu \_0-z_{-}(\alpha / 2) \sigma / \sqrt{ } n, \infty\right] 7$

Where:

n Sample size (60)

$z_{-} \alpha$ Critical value, is 1.645 for $\alpha=0.05$ or confidence level of 0.95 .

$z_{-}(\alpha / 2)$ Equal to $0.1 / 2=0.05$, corresponds to a confidence level of $95 \%$ (1.96).

Replacing the values:

Acceptance interval $=[204.8-1.964 .3 / \sqrt{ } 60, \infty]\left[\mu \_0-z_{-}(\alpha / 2) \sigma / \sqrt{ } n, \infty\right] 8$

Acceptance interval $=[203.7, \infty]$

Table 11. Results of user data rate measurements

\begin{tabular}{|c|c|c|c|c|}
\hline \multirow{2}{*}{ Measurement } & Date & Time & $\begin{array}{c}\text { Down link speed } \\
\text { (down link speed) } \\
\text { (Kbps) }\end{array}$ & $\begin{array}{c}\text { Up link speed } \\
\text { (up link speed) } \\
\text { (Kbps) }\end{array}$ \\
\hline 1 & $25 / 10 / 2018$ & $8: 00-9: 00$ & 817 & 201 \\
\hline 2 & $25 / 10 / 2018$ & $9: 00-10: 00$ & 820 & 208 \\
\hline 3 & $25 / 10 / 2018$ & $10: 00-11: 00$ & 821 & 200 \\
\hline 4 & $25 / 10 / 2018$ & $11: 00-12: 00$ & 816 & 199 \\
\hline 5 & $25 / 10 / 2018$ & $12: 00-13: 00$ & 818 & 204 \\
\hline 6 & $25 / 10 / 2018$ & $14: 00-15: 00$ & 814 & 202 \\
\hline 7 & $25 / 10 / 2018$ & $15: 00-16: 00$ & 823 & 200 \\
\hline 8 & $25 / 10 / 2018$ & $16: 00-17: 00$ & 822 & 198 \\
\hline 9 & $25 / 10 / 2018$ & $17: 00-18: 00$ & 815 & 187 \\
\hline 10 & $26 / 10 / 2018$ & $08: 00-09: 00$ & 818 & 200 \\
\hline 11 & $26 / 10 / 2018$ & $09: 00-10: 00$ & 817 & 201 \\
\hline 12 & $26 / 10 / 2018$ & $10: 00-11: 00$ & 825 & 200 \\
\hline 13 & $26 / 10 / 2018$ & $11: 00-12: 00$ & 817 & 208 \\
\hline 14 & $26 / 10 / 2018$ & $12: 00-13: 00$ & 810 & 203 \\
\hline 15 & $26 / 10 / 2018$ & $14: 00-15: 00$ & 824 & 204 \\
\hline 16 & $26 / 10 / 2018$ & $15: 00-16: 00$ & 818 & \\
\hline & & & & 201 \\
\hline
\end{tabular}




\begin{tabular}{|c|c|c|c|c|}
\hline 17 & $26 / 10 / 2018$ & $16: 00-17: 00$ & 817 & 200 \\
\hline 18 & $26 / 10 / 2018$ & $17: 00-18: 00$ & 819 & 197 \\
\hline 19 & $27 / 10 / 2018$ & $08: 00-9: 00$ & 817 & 199 \\
\hline 20 & $27 / 10 / 2018$ & $09: 00-10: 00$ & 822 & 202 \\
\hline 21 & $27 / 10 / 2018$ & $10: 00-11: 00$ & 815 & 208 \\
\hline 22 & $27 / 10 / 2018$ & $11: 00-12: 00$ & 818 & 208 \\
\hline 23 & $27 / 10 / 2018$ & $12: 00-13: 00$ & 815 & 205 \\
\hline 24 & $27 / 10 / 2018$ & $14: 00-15: 00$ & 821 & 210 \\
\hline 25 & $27 / 10 / 2018$ & $15: 00-16: 00$ & 818 & 204 \\
\hline 26 & $27 / 10 / 2018$ & $16: 00-17: 00$ & 825 & 208 \\
\hline 27 & $27 / 10 / 2018$ & $17: 00-18: 00$ & 818 & 203 \\
\hline 28 & $29 / 10 / 2018$ & $08: 00-09: 00$ & 819 & 209 \\
\hline & & & & 206 \\
\hline 60 & $01 / 11 / 2018$ & $12: 00-13: 00$ & 818 & \\
\hline
\end{tabular}

Source: Author's elaboration

According to the results of the calculations for cabling and hardware requirements, shown in Table 8 and Table 9, the fiber optic cable consists of two types, one with $200 \mathrm{~m}$ span and the other with $300 \mathrm{~m}$ span. The choice of one or the other depends on the magnitude of the cable sag from pole to pole; in addition to the same span between poles. It is possible to select cables with smaller span, hence lower cost, but it implies the realization of additional straight splices and the greater use of hardware accessories. It is also not economically adequate, since fiber optic cable is purchased in $4 \mathrm{~km}$ reels. In this sense, a careful analysis is necessary to achieve a technical and economic compromise in order to minimize materials and costs, but without affecting compliance with the installation requirements listed in Table 1 to Table 6 . In addition, once the external plant is installed, it is necessary to perform a series of optical measurements with various instruments such as OTDR [13] to verify that all elements of the trunk link comply with maximum attenuation parameters and others [14, $15]$.

According to Figure 8, the optical power budget, characterized by the system performance margin, was found to be $6.4715 \mathrm{~dB}$ at minimum transmit power and $15.1715 \mathrm{~dB}$ at maximum transmit power. These results, evaluated in the worst case (at lower transmission power) and in the best case (at higher transmission power) show that the optical trunk has a good margin for possible signal degradation problems due to various factors such as environmental factors, maintenance of connectors, new splices or others. Likewise, the results show that the total attenuation of the cabling system (i.e. power losses due to fiber, splices and connectors that make up the trunk), is only $2.0285 \mathrm{~dB}$. The system gain (i.e., the difference in transmitter and receiver powers) is in the range of $11.1 \mathrm{~dB}$ to $19.8 \mathrm{~dB}$. Also, the total loss budget per link is in the range of 17.2 to $8.5 \mathrm{~dB}$. All these values show that the system has sufficient working margin to cover any loss of power due to various causes such as lack of maintenance, new splices for repair, degradation of components, among others. The calculation procedure followed takes into account all the factors involved and is carried out in detail based on international recommendations. Another important aspect of the optical budget is scattering losses. This type of losses are not included in the results of the optical budget of the present study because they do not manifest themselves at speeds lower than 10 Gbps [6]. It should be noted that the data rate is highly dependent on the power budget; i.e., if the signal power degrades, the rate drops and manifests itself to the user as latencies, intermittency or outages in their service. Unlike the optical system, the satellite system is known to lack robustness and is very sensitive to environmental problems such as rains and electrical environmental phenomena very common in the Peruvian highlands. The proposed alternative, based on fiber as backbone network and wireless as access network, is the best, as these technologies are currently in full expansion and massification.

The coverage simulation shown in Figure 10 shows that the actual signal coverage, and therefore the service, will be available to new users throughout the entire geographical area of the town of Choclococha. The signal level, and therefore the coverage, is also influenced by the frequency band used. The present study uses the free $5 \mathrm{GHz}$ band because it is a band still little used, which helps to avoid interference from signals more common in the $2.4 \mathrm{GHz}$ band [16]. As in the present study, other authors carried out their work considering radios and antennas from the manufacturer Cambium Networks [17, 18, 19]. However, the design process of the radio links was performed with RadioMobile software. Although this software is widely used in academic and professional environments, currently Cambium Networks has become a leader in wireless technologies by 
providing its own point-to-point and point-to-multipoint radio link design software free of charge, which is used in this study.

Table 11 shows the data rate results for the sample under consideration. The data rate indicator actually consists of two speeds, upstream and downstream, being common to indicate commercially only the downstream speed (2 Mbps). The data show that the download speed is always higher than the upload speed. This is in accordance not only with what is commercially offered by telecommunications operators, but also with the fact that Internet users generate more download traffic than upload traffic. For both speeds, the results show variation around the minimum expected value that, according to regulations imposed by the regulatory body, operators must comply with to guarantee minimum service conditions in terms of the data speed contracted by the customer. In rural areas of Peru, the speed proposed by the MTC [8] and that offered by the operators is $2 \mathrm{M}$ bps (downstream); this relatively low speed is appropriate for the low population density, and therefore low traffic, in these areas. A similar situation is reflected in other countries in the region, such as Colombia, where $2 \mathrm{M}$ bps is also offered to public institutions as part of the country's broadband plan [20].

$2 \mathrm{Mbps}$ is the lowest and most economical speed, appropriate for introducing digital services in rural areas. As traffic per user increases, the speed offered increases. For example, in Cajamarca, 4Mbps is offered to users in the cities [21]. Of the $2 \mathrm{Mbps}$ downstream, only $40 \%$ is guaranteed; for upstream, the speed offered is $512 \mathrm{Kbps}$ and, likewise, only $40 \%$ is guaranteed. Thus, the optical system guarantees only $819.2 \mathrm{Kbps}$ downstream (40\% of $2 \mathrm{Mbps}$ ) and $204.8 \mathrm{Kbbps}$ upstream ( $40 \%$ of $2 \mathrm{Mbps}$ ). Compared to the satellite system, very common in isolated rural areas or areas with difficult access, and usually used by private companies and some state entities, it guarantees only $15 \%$ of the contracted speed [22]. Thus, it only guarantees $76.8 \mathrm{Kbps}$ downstream ( $15 \%$ of $512 \mathrm{Kbps})$ and $19.2 \mathrm{Kbps}$ upstream $(15 \%$ of $128 \mathrm{Kbps})$. These results are far below those offered by the optical system. These wide speed differences in favor of the optical system translate into a better quality of service. Another result of satellite speed measurements was obtained in a study carried out in Huancavelica, similar to the present work, which showed an average download and upload speed of $10 \mathrm{Kbps}$ [17]. It should be noted that the data rate is highly dependent on the power budget, i.e., if the signal power degrades, the speed drops and manifests itself to the user as latency, intermittency or cuts in service. Unlike the optical system, the satellite system is known to lack robustness and is very sensitive to environmental problems such as rains and electrical environmental phenomena very common in the Peruvian highlands. A study carried out to evaluate technological alternatives for rural areas, mentioned that the typical speed for Internet service using satellite technology is $600 \mathrm{Kbps}$ and concludes that, among the decision criteria, is the technological one: the alternative must provide quality of service and potential for future expansion, so it recommended that the alternative based on fiber as backbone and wireless as access network is the best [23]. The analysis of VSAT satellite technology used in rural areas provides positive reasons in favor of optical technology, which is currently booming and becoming more widespread [24, 23].

Finally, with respect to the reception level of the wireless signal (Table 10), this takes values above the minimum power recognizable by the client's receiving equipment. Similar measurements and results with a sample of only 31 measurements showed that the received power is higher than the minimum recognizable by the wireless receiving equipment located at the user's premises [17]. Similar works aimed at improving telecommunications in the provinces of Bagua and Santa Cruz, respectively, considered in their results the minimum reception power to ensure that the wireless signal is recognized by the receiving equipment $[18,19]$. This minimum power, specified by the manufacturer of the equipment used, is, for the present study, $-86 \mathrm{dBm}$. Unlike the data rate, the values obtained for the reception power cannot be lower than the minimum specified by the manufacturer; if such a situation were to occur, it would imply that the service would be affected. The data in Table 10 also show that the power received by the client takes lower values in those geographical points (given by their coordinates) farther away from the transmitting antenna (located at the Choclococha node). As the measurement points are closer to the transmitting antenna, the signal power received by the client is higher. The worst case corresponds to measurement 1 in which a reception power of $-78 \mathrm{dBm}$ was obtained, $12 \mathrm{~dB}$ above the minimum acceptable. This margin can counteract eventual communication problems such as those due to environmental factors. However, unlike satellite systems, it would not affect all users equally, but only those located farther away from the transmitting antenna. The results show that the signal coverage, and therefore the service, is available throughout the geographical area of the town of Choclococha and is fully available to new users. The signal level is also influenced by the frequency band used. The present study uses the free $5 \mathrm{GHz}$ band because it is a band still little used, which helps to avoid interference from signals more common in the $2.4 \mathrm{GHz}$ band, keeping similarities with other equivalent studies [18]. As in the present study, other authors conducted their work considering radios and antennas from the manufacturer Cambium Networks $[17,18,19]$. However, the design process of the radio links was performed with RadioMobile software. Although this software is widely used in academic and professional environments, currently Cambium Networks [25] has become a leader in wireless technologies by providing its own point-to-point and point-tomultipoint radio link design software free of charge, which is used in this study. 


\section{Conclusions}

According to the results and calculations performed, it was verified that the average value obtained for download speed $(819.1 \mathrm{Kbps})$ is higher than $818.32 \mathrm{Kbps}$; that is, it is within the interval defined for a confidence level of 0.95. Similarly, it was verified that the average value obtained for the upload speed (204.3 $\mathrm{Kbps}$ ) is greater than $203.7 \mathrm{Kbps}$; that is, it is within the interval defined for a confidence level of 0.95 . These verifications not only verify the expected values, but also provide a guarantee of quality of service.

Likewise, it was verified that the average value obtained in the reception power measurements $(-63.9 \mathrm{dBm})$ was higher than the lower limit $(-88.02 \mathrm{dBm})$ of the interval defined for a confidence level of 0.95 ; that is, it is within that interval. Therefore, it is guaranteed that the wireless system provides coverage throughout the user locality.

On the other hand, the design of a network, using optical fiber as the backbone link and PMP radios as the subscriber access network, provides a viable solution to the lack of telecommunications systems with quality of service in the town of Choclococha, located in the Huancavelica region. Thus, the quality of service is guaranteed by using optical fiber, which is immune to interference; in addition, its operability complies with link characterization tests and quality parameters such as jitter, latency, throughput and packet losses [26, 10]. The use of optical fiber as a backbone network completely overcomes the problems associated with the use of satellite communication, which is very sensitive to environmental conditions. In this sense, this factor is practically ruled out and not only the quality but also the availability of the service is guaranteed.

Fiber optic communications are characterized by their high bandwidth. They are used to provide various voice, data and video services simultaneously to subscribers at much higher speeds than other technologies. Likewise, since optical networks have greater bandwidth, they can serve a larger number of subscribers. Compared to satellite services, optical networks offer the subscriber the advantage of easily increasing bandwidth. By supporting high speeds, optical networks allow the user to contract or access digital content or services that require not only more bandwidth, but also more powerful and modern equipment. In this sense, the user can have computers and other media, such as laptops, tablets and smartphones, with which to access and benefit from the high bandwidth of optical networks. This feature goes hand in hand with the simultaneous use of several devices at the same time without loss of speed. Optical networks also have an impact on increasing Internet access coverage. With more bandwidth, services can be distributed to a greater number of users or beneficiaries in the town of Choclococha.

The cost of fiber optic Internet access service is considerably reduced compared to other technologies such as satellite. For the same bandwidth, the cost of service based on optical networks is considerably lower than with other technologies. The tariffs for home Internet access service will be determined by the operator and will be subject to the tariff regime supervised by OSIPTEL [22].

The graphical application developed, using Matlab, allowed the sizing and verification of the optical power budget of the link between the end nodes. Through this application, the designer can check the effect of various parameters or elements that determine the power budget such as: minimum and maximum transmitter power, maximum power allowed by the receiver, receiver sensitivity, link length, number of splices and connectors, wavelength and parameters stipulated by the standards or given by the manufacturers.

Finally, the use of wireless systems based on multipoint sectorial antennas with the capacity to serve a large number of users at the same time has a positive influence on the increase of both client and geographic coverage by providing bandwidth, beamwidth and range that meet current and future requirements.

\section{Bibliography}

[1] MTC: Agenda Pendiente, Sector Comunicaciones. Viceministerio de Comunicaciones [cited 2019 Dec 09]. Available from: http://www.congreso.gob.pe/Docs/comisiones2018/Transportes/files/forotelecomunicaciones/mtc_vmc 8n ov nakagawa.pdf.

[2] INEI. Huancavelica - Compendio Estadístico [cited 2019 Nov 12]. Available from: https://www.inei.gob.pe/media/MenuRecursivo/publicaciones digitales/Est/Lib1494/libro.pdf.

[3] GSMA: Inclusión digital en América Latina y el Caribe [cited 2020 Ene 25]. Available from: http://disde.minedu.gob.pe/handle/123456789/4766?show=full.

[4] Garmin: BaseCamp. [cited 2019 Set 27]. Available from: https://www.garmin.com/esES/shop/downloads/basecamp.

[5] ZTT. All Dielectric Self Supporting Cable - ADSS. USA: ZTT; 2018 [cited 2019 Oct 16]. Available from: http://zttcable.com/solution/show-218.html

[6] Anritsu: Dispersion in Optical Fibers; 2010 [cited 2019 Nov 14]. Available from: http://dl.cdnanritsu.com/en-us/test-measurement/files/Technical-Notes/WhitePaper/Disp_in_Opt_Fibers_PMD_CD.pdf.

[7] Chomycz B. Fiber Optic. Installer's Field Manual. New York: McGraw-Hill; 2000.

[8] NECA/FOA: NECA/FOA 301-2016, Standard for Installing and Testing Fiber Optics [cited 2020 Ene 24]. Available from: https://www.thefoa.org/tech/ref/1pstandards/NECA301-16_P.pdf 
[9] FITEL. Instalación de banda ancha para la conectividad integral y desarrollo social de la región Huancavelica. Perú: Ministerio de Transportes y Comunicaciones; 2014.

[10] BICSI: Optical Link Budget; 2019 [cited 2019 Nov 14]. Available from: https://www.bicsi.org/educationcertification/education-@-bicsi-learning-academy/technical-publications/bicsi-library.

[11] IEEE: $\quad$ MetroEthernet [cited $2020 \quad$ Feb 16$]$ Available from: http://www.ieee.org.ar/downloads/metroethernet.pdf.

[12] Cambium Networks: LINKPlanner-Design Networks; 2019 [cited 2019 Nov 28]. Available from: https://www.cambiumnetworks.com/products/management/linkplanner/.

[13] EXFO: FTB-735C-metro/PON FTTx/MDU OTDR; 2019 [cited 2019 Dec 09]. Available from: Recuperado de https://www.exfo.com/es/productos/pruebas-de-redes-de-campo/otdr-y-iolm/ftb-735c/

[14] Collings B. Heismann F. Lietaert G. Reference Guide to Fiber Optic Testing. 2nd ed. USA: JDS Uniphase Corporation; 2010.

[15] VIAVI: Key Test Practices that Minimize Optical Network Downtime [cited 2020 Jan 07]. Available from: https://comms. viavisolutions.com/lp-cmp?cp=vi102264\&th=std\&lang=en

[16] UIT: Propagación de las ondas radioeléctricas [cited 2020 Jan 24]. Available from: https://www.itu.int/rec/R-REC-P/es

[17] Fernández L, Sánchez P. Servicio de Internet mediante fibra óptica y radio enlace en la institución educativa Túpac Amarú del distrito de Palca. Huancavelica: Universidad Nacional de Huancavelica; 2014.

[18] Elías M. Diseño de una red de transporte de fibra óptica y de acceso inalámbrico para mejorar el acceso a los servicios de telecomunicaciones y lograr la conectividad integral de la provincia de Bagua. Trujillo, Perú: Universidad Nacional Pedro Ruiz Gallo; 2016.

[19] Guerrero B. Estudio del diseño de una red de banda ancha usando una red de transporte de fibra óptica y tecnología WiMax en la red de acceso para demostrar la mejora de los servicios de telecomunicaciones en la provincia de Santa Cruz. Trujillo: Perú, Universidad Nacional Pedro Ruiz Gallo; 2017

[20] Rodríguez D. Diseño de red troncal SDH con fibra óptica para el sur de Ecuador. Ecuador: Escuela Politécnica Nacional; 2001.

[21] Fernández C. Diseño de una red de banda ancha para la región Cajamarca. Lima: Pontificia Universidad Católica del Perú; 2013.

[22] OSIPTEL: NECA/FOA 301-2016, Ficha informativa de tarifas de internet satelital. [cited 2019 Dec 09]. Available from: https://serviciosweb.osiptel.gob.pe/ConsultaSIRT/Buscar/FrmVerTarifa.aspx?pTarifa=137529f

[23] Cruz M. Análisis comparativo de soluciones tecnológicas para la formulación de un proyecto de telecomunicaciones rurales: redes ópticas y VSAT. Lima: Universidad San Martín de Porres; 2010.

[24] Montes L. Modelo de rd de acceso para poblados rurales sin servicio de telecomunicaciones en el Perú-. Lima: Pontificia Universidad Católica del Perú; 2013.

[25] Cambium Networks: PMP Products \& Solutions; 2018 [cited 2019 Dec 12]. Available from: https://www.cambiumnetworks.com/products/pmp-distribution/.

[26] Nuñez-Lira LA, Rosario-Villarreal MA, Márquez-Camarena JF, \& Mariño-Arroyo JB. Evaluation of a wireless Broadband Network for VoIP in Huaytará. Enfoque UTE 2019; 10 (4): 28-44. doi: 10.29019/enfoque.v10n4.513 